\title{
Occasional abstract
}

Journal of Medical Genetics, 1981, 18, 142-143

\section{Inherited abnormalities of collagen}

A recent editorial ${ }^{1}$ in the New England Journal of Medicine draws attention to the advances in collagen chemistry which have led to a much better understanding of inherited collagen abnormalities such as the Ehlers-Danlos syndrome (EDS) and osteogenesis imperfecta (OI). There are now seven subgroups of EDS and five of OI, every one of which is itself variable. The situation closely resembles the inherited haemoglobinopathies with the added interest that collagen is much larger, has five genetic types with eight different chains, and is much more widely distributed in tissues as diverse as bone, skin, blood vessel, lung, tendon, and glomerulus. Thus the disease potential is enormous.

Just as haemoglobin chain deletions cause $\alpha$ and $\beta$-thalassaemias, so collagen chain deletions produce specific inherited diseases. EDS IV with type III collagen deficiency varying from zero to several percent $^{23}$ causes death from lethal arterial rupture in those most severely affected. Deletion of the $\alpha 2$ chain of type I collagen ${ }^{4}$ causes moderately severe thin boned OI congenita. An $\alpha 1$ (I) chain deletion would probably be lethal as would type II and type IV collagen deletions.

Post-ribosomal modifications of collagens include lysine hydroxylation, $\varepsilon$ amino crosslinks, and excision of procollagen extension peptides from secreted collagens.

Inherited defects of each step produce specific diseases which are also proving heterogeneous. EDS V has been described with ${ }^{5}$ and without ${ }^{6}$ lysyl oxidase deficiency. Byers $e t \mathrm{al}^{7}$ have recently clearly identified lysyl oxidase deficiency in an $\mathrm{X}$ linked form of cutis laxa, resulting in faulty crosslink formation. EDS VI, in which scoliosis, retinal detachment, and arterial rupture complicate otherwise typical EDS, has hydroxylysine deficient ${ }^{8}$ and normal forms (McKusick, 1980, personal communication). Procollagen peptidase deficiency in animals causes a lethal disease (dermatosparaxis) ${ }^{9}$ in which collagen fibril formation is interfered with by the persisting extensions. The puzzling benignity of the human variant ${ }^{10}$ EDS VII has recently been explained (Steinemann, 1979, personal communication) by an amino-acid substitution at the cleavage site which allows the $\mathrm{N}$ terminal extension to persist.
Diseases analogous to sickle cell and haemoglobin $\vec{\circ}$ $\mathrm{C}$ disease (from amino-acid substitution within the $\vec{\overrightarrow{ }}$ collagen molecule) are so far unidentified. Possibly $\sigma_{\sigma}$ single substitutions in the much larger molecule produce such insignificant changes as not to produce clinical disease or to be undetectable by electro- $\vec{\infty}$ phoresis. Amino-acid substitutions within the $i v$ procollagen extension peptides do produce disease, $\vec{A}$ however. EDS VII, as mentioned already, is caused ${ }^{N}$ by a mutation resulting in inefficient cleavage, and a 5 recently described $\mathrm{OI}$ tarda variant ${ }^{11}$ has a probable $\overrightarrow{ }$ substitution which allows over-glycosylation and $\frac{}{0}$ subsequent insolubility of procollagens. We may also expect that chain termination mutations $\vec{\circ}$ analgous to haemoglobin Constant Spring will be $\stackrel{\infty}{\rightarrow}$ detected among these diseases.

When modern molecular biological techniques allow the identification of specific collagen genes for $\alpha 1(\mathrm{I}), \alpha 2$, and $\alpha 1$ (III), then the way is clear with cloning and restriction enzyme techniques to allow $\frac{\circ}{\mathbb{D}}$

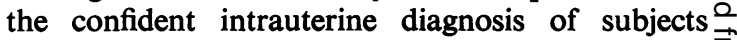
affected by these mutations, just as is already pos- 0 sible in some thalassaemias.

Already (theoretically) EDS IV and the $\alpha 2$ chain OI mutant could be diagnosed by fetoscopic skin biopsy if the need and opportunity arises. The vast majority of these diseases, however, are not identi- $-\frac{0}{-}$ fiable in this way.

These collagen abnormalities are also relevant to the more common diseases. Osteoporosis and $\frac{\mathrm{O}}{3}$ cerebral aneurysms are obvious examples in which genetic defects similar to those mentioned above could be to blame.

F M POPEN

MRC Clinical Research Centre, Northwick Park Hospital, Harrow, Middlesex HA1 3UJ. N

\section{References}

1 Editorial. N Engl J Med 1980;303:101-2.

2 Pope FM, Martin GR, Lichtenstein JR, et al. Patients with Ehlers-Danlos syndrome type IV lack type III? collagen. Proc Natl Acad Sci USA 1975;72:1314-6.

3 Pope FM, Martin GR, McKusick VA. Inheritance of Ehlers-Danlos type IV syndrome. J Med Genet 1977 14:200-4.

4 Nicholls AC, Pope FM, Schloon H. Biochemical heterogeneity of osteogenesis imperfecta: a new variant. Lance?
$1979 ; \mathbf{i}: 1193$. 
5 DiFerrante N, Leachman RD, Angelini P, Dunnell PV, Francis G, Almazan A. Lysyl oxidase deficiency in Ehlers-Danlos syndrome type V. Connect Tissue Res $1975 ; 3: 49-53$.

6 Siegel RC, Black CM, Bailey AJ. Cross-linking of collagen in the X-linked Ehlers-Danlos type V. Biochem Biophys Res Comm 1979;88:281-7.

7 Byers PH, Siegel RC, Holbrook KA, Narayanan AS, Bornstein P, Hall JG. X-linked cutis laxa. $N$ Engl J Med $1980 ; 303: 61-5$.

8 Pinnell SR, Krane SM, Kenzora JE, Glimcher MJ. A heritable disorder of connective tissue: hydroxylysine- deficient collagen disease. $N$ Engl J Med 1972;286: 1013-20.

9 Helle $\mathrm{O}, \mathrm{Nes}$ NN. A hereditary skin disease in sheep. Acta Vet Scand 1972;13:443-5.

10 Lichtenstein JR, Martin GR, Kohn LD, Byers PH, McKusick VA. Defect in conversion of procollagen in a form of Ehlers-Danlos syndrome. Science 1974;182: 298-300.

11 Peltonen L, Palotie A, Hayashi T, Prockop DJ. Thermal stability of type I and type III procollagens from normal human fibroblasts and from a patient with osteogenesis imperfecta. Proc Natl Acad Sci USA 1980;77:162-6. 